\title{
The diversity of participants of the Austrian Citizen Science Conference from 2015-2020
}

\section{Daniel Dörler, ${ }^{a, *}$ and Florian Heigl ${ }^{a}$}

${ }^{a}$ University of Natural Resources and Life Sciences, Vienna,

Gregor-Mendel-Str. 33, 1180 Vienna, Austria

*E-mail: daniel.doerler@boku.ac.at; florian.heigl@boku.ac.at

\section{Abstract}

In this extended abstract we investigate if the diversity represented in the Citizen Science Network Austria is also reflected in the participants of the Austrian Citizen Science Conference, the main annual event of the Citizen Science Network Austria. The results indicate that the diversity has increased since 2015. However, some groups are still only a minority at the conference.

Vienna - Austria 


\section{Introduction}

In recent years citizen science (cs) networks on a national level have been established in many countries across Europe [1]. The main tasks of these networks are to present a variety of cs projects to an interested public, to foster knowledge exchange between cs practitioners and to create awareness for this methodology in research, society and policy [2]. One key element to achieve these goals for many national cs networks is a regular event, where the community can meet and interact.

Cs has always been a very diverse field of research, both in terms of academic disciplines using this methodology and of people involved in or coordinating such projects. This diversity is a unique feature of cs and both a challenge and an opportunity [3]. On the one hand cs profits from bringing together people from a variety of backgrounds. On the other hand, it also challenges project coordinators to create a level field for this diversity of people to foster collaboration on eye-level.

This unique feature of cs is also important to consider when planning cs activities. Since the early 2010s many cs events have been organized across Europe, e.g. the biannual conference of the European Citizen Science Association, the Forum Citizen Science in Germany and the Austrian Citizen Science Conference (ACSC). This raises the question if these events can really live up to the expectations to provide a space for the diversity of the respective cs community.

In this extended abstract we are investigating whether the ACSC was able to attract the wide range of the Austrian cs community and how different circumstances might have affected this diversity as a whole.

\section{Material and Methods}

To assess the diversity of the participants we analysed the registrations for each conference and classified them according to the following categories:

- Universities: public and private universities

- Associations: civil non-profit-organizations with a clear monothematic goal

- Companies: organizations with an economic organization structure (including many extra-mural research facilities)

- Museums

- Universities of Applied Sciences: institutions of higher education focusing on applied science or art which do not offer doctoral degree programs

- Citizens: participants providing no institutional background or registering with a private e-mail-address

- Public authorities: institutions monitoring, regulating or maintaining public property

- Funding organizations: organizations providing funding as a main task

- Pedagogical Universities: institutions of higher education responsible for the training of teachers

- Academy of Sciences: a type of learned society dedicated to research

- National parks: nature reserves protected by federal law (including nature parks)

In 2015 and 2016 people only registered with their name and an e-mail-address. If the email-address used for registration was indicating an institutional background (e.g. name@boku.ac.at) we counted the person for the respective category; if it was a private e-mail- 
address (e.g. name@hotmail.com) we counted the person as a citizen. From 2017 onwards registration also optionally included the background of the participants. Therefore, we only used the e-mail-addresses for background assessment if no information on the institutional background was provided.

\section{Results}

The diversity of institutional backgrounds of participants has increased over the years (Fig. 1). In 2015 and 2016 participants came from seven different backgrounds, whereas in 2019 and 2020 the participants came from ten or eleven different backgrounds, respectively.

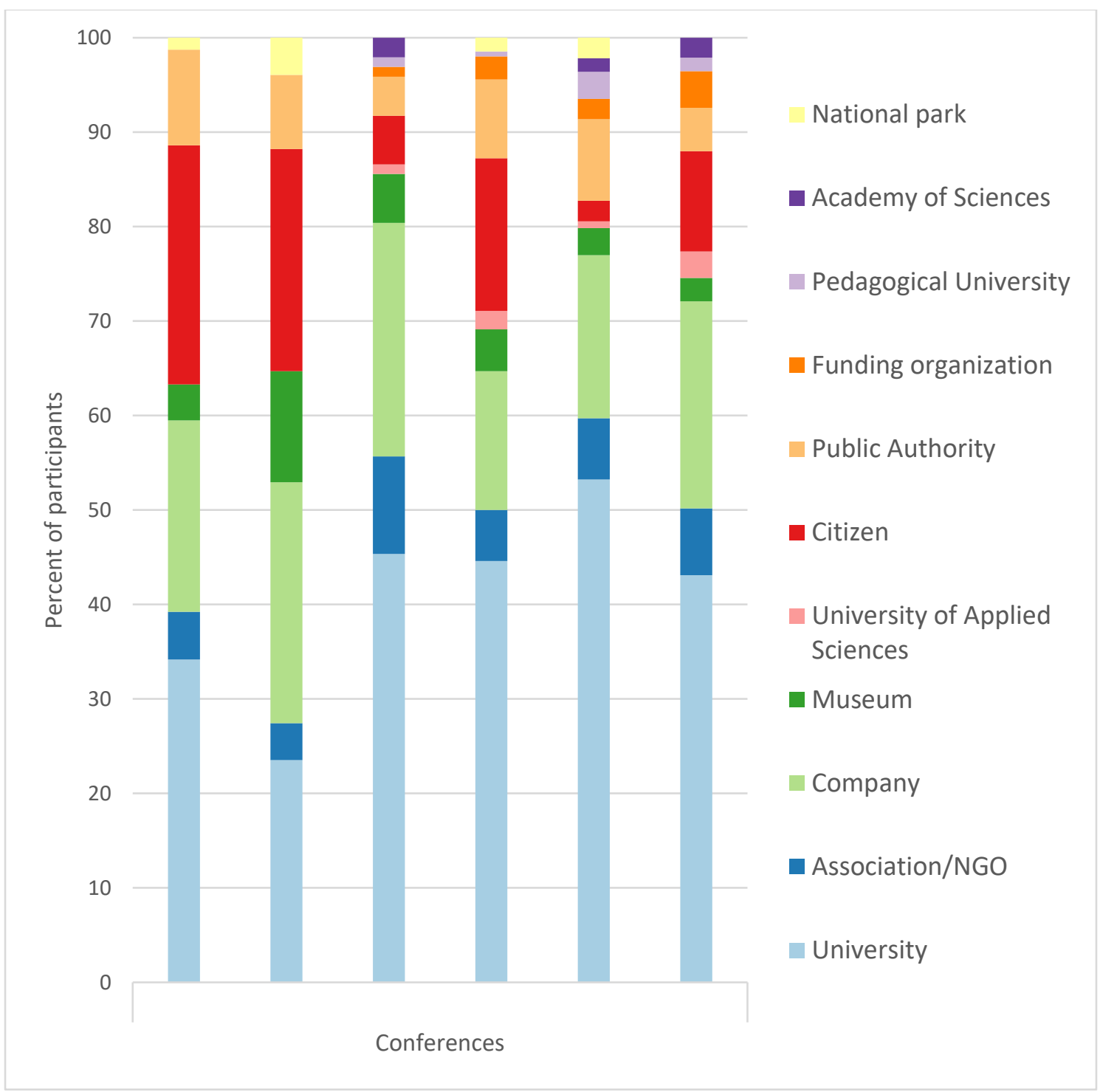

Fig. 1: The institutional diversity of participants at the ACSC from 2015 to 2020 displayed in percentages of participants.

Participants from universities and companies have always represented the main participant groups of the Austrian Citizen Science Conference (Tab. 1). 
Tab. 1: Number and categorization of participants at the ACSC from 2015-2020.

\begin{tabular}{|c|c|c|c|c|c|c|c|c|c|c|c|c|c|c|}
\hline & \multicolumn{2}{|c|}{ ACSC 2015} & \multicolumn{2}{|c|}{ ACSC 2016} & \multicolumn{2}{|c|}{ ACSC 2017} & \multicolumn{2}{|c|}{ ACSC 2018} & \multicolumn{2}{|c|}{ ACSC 2019} & \multicolumn{2}{|c|}{ ACSC 2020} & \multicolumn{2}{|c|}{ Total } \\
\hline & Abs. & $\%$ & Abs. & $\%$ & Abs. & $\%$ & Abs. & $\%$ & Abs. & $\%$ & Abs. & $\%$ & $\begin{array}{l}\text { Overall } \\
\text { variance } \\
\text { (Abs.) }\end{array}$ & $\begin{array}{l}\text { Overall } \\
\text { variance }(\%)\end{array}$ \\
\hline $\begin{array}{l}\text { Total } \\
\text { participants }\end{array}$ & 79 & & 51 & & 97 & & 204 & & 139 & & 283 & 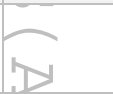 & 80 & \\
\hline University & 27 & 34.2 & 12 & 23.5 & 44 & 45.4 & 91 & 44.6 & 74 & 53.2 & 122 & 43.1 & 38 & 9.5 \\
\hline Association/NGO & 4 & 5.1 & 2 & 3.9 & 10 & 10.3 & 11 & 5.4 & 9 & 6.5 & 20 & 7.1 & 6 & 2.0 \\
\hline Company & 16 & 20.3 & 13 & 25.5 & 24 & 24.7 & 30 & 14.7 & 24 & 17.3 & 62 & 21.9 & 16 & 3.8 \\
\hline Museum & 3 & 3.8 & 6 & 11.8 & 5 & 5.2 & 9 & 4.4 & 4 & 2.9 & 7 & 2.5 & 2 & 3.1 \\
\hline $\begin{array}{l}\text { University of } \\
\text { Applied Sciences }\end{array}$ & 0 & 0 & 0 & 0 & 1 & 1.0 & 4 & 2.0 & 1 & 0.7 & 8 & 2.8 & 3 & 1.0 \\
\hline Citizen & 20 & 25.3 & 12 & 23.5 & 5 & 5.2 & 33 & 16.2 & 3 & 2.2 & 30 & 10.6 & 12 & 8.7 \\
\hline Public Authority & 8 & 10.1 & 4 & 7.8 & 4 & 4.1 & 17 & 8.3 & 12 & 8.6 & 13 & 4.6 & 5 & 2.2 \\
\hline $\begin{array}{l}\text { Funding } \\
\text { organization }\end{array}$ & 0 & 0 & 0 & 0 & 1 & 1.0 & 5 & 2.5 & 3 & 2.2 & 11 & 3.9 & 4 & 1.4 \\
\hline $\begin{array}{l}\text { Pedagogical } \\
\text { University }\end{array}$ & 0 & 0 & 0 & 0 & 1 & 1.0 & 1 & 0.5 & 4 & 2.9 & 4 & 1.4 & 2 & 1.0 \\
\hline $\begin{array}{l}\text { Academy of } \\
\text { Sciences }\end{array}$ & 0 & 0 & 0 & 0 & 2 & 2.1 & 0 & 0 & 2 & 1.4 & 6 & 2.1 & 2 & 1.0 \\
\hline National park & 1 & 1.3 & 2 & 3.9 & 0 & 0 & 3 & 1.5 & 3 & 2.2 & 0 & 0 & 1 & 1.3 \\
\hline
\end{tabular}


Participants from universities and citizens have the highest variance from all participant groups (universities: $+/-9.5 \%$, citizens: $+/-8.7 \%$ ), participants from the academy of sciences and pedagogical universities have the lowest fluctuation rate (1\%). Four groups of participants have not been part of the conference in the years 2015 and 2016 but have appeared in most of the years after: universities of applied sciences, funding organizations, pedagogical universities and the academy of sciences.

If we look at the overall participant numbers at all conferences, we can see a rise in participant numbers from 79 in 2015 to 283 in 2020, which means that the numbers have more than tripled in six years.

\section{Discussion and Conclusion}

The aim of this extended abstract was to evaluate if the ACSC is reaching its goal to be attractive to a wide variety of cs practitioners. The results indicate that the diversity has indeed increased since 2015. In the years 2017-2020 11 different participant groups have registered for the conference in contrast to 7 in 2015.

One reason for this rise in diversity could be that in 2015 and 2016 we could only use email-addresses to assess the background of the registered persons, whereas in the following years an institutional background was provided often as well. In some cases, we could see that people registered with private e-mail-addresses although they provided an institutional background during the registration. These cases were then classified according to this institutional background rather than based on the e-mail-address used for registration. This could have resulted in an underestimation of the institutional diversity and a resulting overestimation of citizen attendance in 2015 and 2016.

Over the years, we have increased our efforts to reach people outside the universities. To this aim, we wrote press releases for the conferences, but also sought direct contact with nonuniversity research institutions and increased our social media performance. As a result, we have been able to respond more to the needs of these organizations. For example, one result was that the conference was held at different locations in Austria. It also shows that the conference is not shaped by just one organization but can be supported by the entire network and shaped accordingly. We think that this openness and the consideration of the needs of non-university institutions has contributed to the fact that the field of participants has become more diverse over the years. However, we can also see rather high fluctuations in some participant groups (e.g. universities and citizens) and some groups that only make up a small proportion of the overall participants (e.g. national parks, pedagogical universities). Especially the latter groups are important to establish as regular conference participants because they offer unique perspectives very valuable to cs. Therefore, it should be a focus to make the conference more attractive for these groups, without losing other, already rather strong groups. Furthermore, the conference location is probably an important factor when attending the conference. The conferences in 2016 and 2019 were taking place in remote villages, so travels were complex.

Overall, we can conclude that the diversity of represented groups in the ACSC is relatively high. However, in the future, we would like to achieve a greater balance between the different groups in order to make the discussions at the conference even more diverse and to be able to bring in as many points of view as possible. 


\section{Acknowledgements}

We would like to thank all participants of the Austrian Citizen Science Conferences since 2015, all the funders of the conferences and special thanks go out to our local partners, who helped us transforming a diverse group of people into a community.

\section{References}

[1] M Manzoni, K Vohland, S Schade, D Dörler, F Heigl, 2019, COST Action 15212 - Working Group 3 Workshop " Recommendations for the development of (national) Citizen Science Strategies,

Vienna, Austria

[2] H Liu, D Dörler, F Heigl, S Grossberndt, 2021, Citizen Science Platforms. In: Vohland K, LandZandstra A, Ceccaroni L, Lemmens R, Perelló J, Ponti M, Samson R, Wagenknecht K eds. The Science of Citizen Science. Cham: Springer International Publishing, 439-459. DOI: 10.1007/978-3030-58278-4.

[3] MM Haklay, D Dörler, F Heigl, M Manzoni, S Hecker, K Vohland, 2019, What Is Citizen Science? The Challenges of Definition, DOI: 10.1007/978-3-030-58278-4 